\title{
Elaborações em retrospectiva: afeto deprimido na gestação e posterior separação
}

Mariana Reis Barcellos

Rebeca Nonato Machado

Terezinha Féres-Carneiro

\section{RESUMO}

Este artigo é fruto de uma pesquisa mais ampla sobre separação ocorrida durante a transição para a parentalidade a partir da vivência feminina. Teve como objetivo investigar os afetos vivenciados durante a gestação por mulheres que, posteriormente, se separaram. Como referencial teórico, nos embasamos na psicanálise, na abordagem sistêmica e em estudos psicossociais, de modo a abarcar o fenômeno em suas dimensões psicodinâmicas, relacionais e sociais. Foram realizadas 12 entrevistas, que tiveram como base um roteiro oculto semiestruturado, com mulheres das camadas médias da população carioca, entre 30 e 40 anos de idade que se separaram há, no mínimo, dois anos, no período de zero a dois anos de idade do primeiro filho. Os resultados evidenciaram a presença de tristeza e rejeição das participantes em relação à gestação e à relação conjugal. Observamos que a depressão gestacional foi vivenciada por muitas delas, havendo um luto intenso relacionado à passagem da mulher-filha para a mulher-mãe, concomitantemente ao luto pela conjugalidade posteriormente desfeita.

Palavras-chave: Gravidez; depressão; transição para a parentalidade; separação conjugal.

\section{ABSTRACT}

\section{Título do artigo em outro idioma: Subtítulo subtítulo}

This article is the result of a broader research on separation that occurred during the transition to parenting, based on the female experience. The objective of this study was to investigate the affections experienced during pregnancy by women who later separated. As a theoretical framework, we based ourselves on psychoanalysis, the systemic approach and psychosocial studies, in order to encompass the phenomenon in its psychodynamic, relational and social dimensions. Twelve interviews were conducted, which were based on a semi-structured hidden script, with women from the middle classes of Rio Janeiro, between 30 and 40 years of age, who had been separated for at least two years ago, in the period from zero to two years of age of the first child. The results showed the presence of sadness and rejection of the participants in relation to pregnancy and marital relationship. We observed that gestational depression was experienced by many of them, with intense mourning related to the transition from woman-daughter to woman-mother, concomitantly with mourning for the conjugality subsequently broken.

Keywords: Pregnancy; depression; transition to parenthood; marital separation.

As vivências da gestação têm sido objeto de estudos sob diversas orientações teóricas. No presente estudo privilegiaremos autores das abordagens sistêmica e psicanalítica. Compreendendo a gravidez como o período de maior transformação na vida da mulher, alcançando as relações interpessoais, o trabalho, o lazer, os hábitos alimentares, o sono, o corpo, os aspectos psicológicos, as roupas e o seu papel social, é evidente a vulnerabilidade imposta por esse momento. Silva (2014) explica que essas mudanças contribuem para o desenvolvimento de doenças mentais, identificando a depressão como o transtorno que mais acomete a mulher grávida no Brasil.

\section{Sobre os autores}

M. R. B.

https://orcid.org/0000-0001-

9916-6702

Pontifícia Universidade Católica do Rio de Janeiro (PUC-Rio). mari_rbarcellos@hotmail.com

R. N. M.

https://ordic.org/0000-00029465-1570

Pontifícia Universidade Católica do Rio de Janeiro (PUC-Rio). recanm@gmail.com

\section{T. F.}

https://orcid.org/0000-0002-

0564-7810

Pontifícia Universidade Católica do Rio de Janeiro (PUC-Rio). teferca@puc-rio.br

\section{Direitos Autorais}

Este é um artigo de acesso aberto e pode ser reproduzido livremente, distribuído, transmitido ou modificado, por qualquer pessoa desde que usado sem fins comerciais. 0 trabalho é disponibilizado sob a licença Creative Commons CC-BY-NC.

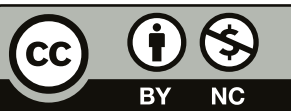




\section{H* INTERACÃO EM PSICOLOGIA}

Na concepção da autora, pensar em gravidez nos leva a considerar mecanismos de fusão e separação, na medida em que o bebê é e não é parte da mãe, simultaneamente. Surgem questionamentos sobre a interface entre as transformações fisiológicas e psíquicas, sobre como os afetos são percebidos e significados ou mesmo escondidos e negados. 0 entusiasmo na gravidez, reforçado pelas crenças populares, camufla aspectos inconscientes que emergem por meio da experiência do desconhecido, representado pelo bebê.

Na mesma perspectiva, Bydlowiski (2002) conceitua a gravidez como um momento em que as representações mentais da mãe em relação ao filho facilitam o acesso ao passado e a redução da barreira da censura. Ao reeditar o seu bebê interno, a mulher atravessa uma regressão libidinal e entra em contato com conteúdos pré-edípicos, experimentando a ambivalência afetiva na gestação. Winnicott (1956) postula esse fenômeno como o estado de preocupação materna primária que tem início ainda durante o final da gravidez e é caracterizado pela identificação da mãe com o bebê, pela regressão psíquica da mulher, pelo aumento da sensibilidade e da intensidade dos afetos nesse período.

A vulnerabilidade experimentada pela mulher grávida possibilita que ela construa um ambiente interno para o bebê. Golse e Bydlowski (2002) identificam essa condição de permeabilidade entre afetos conscientes e inconscientes como transparência psíquica, a partir da qual o bebê pode ser representado por conteúdos e fantasmas reprimidos que retornam do passado. Nessas condições, o filho precisa ser imaginado ao longo da gestação para que seja investido como real após o nascimento. Dessa forma, a gravidez é a possibilidade de exercício psicológico para que os pais experimentem o bebê dentro de si para que ele possa ser percebido em sua alteridade, como outro (Brazelton \& Cramer, 1992).

A polaridade amor-ódio manifesta pulsões construtivas e destrutivas da mulher. Rena et al. (2014) resgatam a concepção freudiana sobre feminilidade e maternidade, na qual ser mãe solucionaria a castração feminina, ao colocar o bebê no lugar do falo perdido. Na vertente fálica, a gravidez poderia solucionar, em parte, o narcisismo para a mulher. Pois, como ressalta Zucchi (2000), o filho representa o paradoxo entre ser a extensão da mãe e a radicalidade de ser outro, concomitantemente. Assim, a destrutividade pode ser dirigida por temores diante do estranhamento e assumir caráter melancólico ante a irreversibilidade da posição materna.

Moura (2013) explica a ambivalência como afeto estruturante das relações objetais, na medida em que amor e ódio figuram-se por meio da fusão e da separação com o outro. Segundo a autora, a ambivalência materna coloca o filho ora como suplente fálico, ora como operador da castração. A nosso ver, a maternidade impõe à mulher o confronto com a falta diante da completude ilusória, com a impossibilidade de satisfação plena, com o real.

Para Solano-Suarez (2014), algumas mulheres experimentam a gravidez como um período gerador de angústia no qual identificam o filho como o estrangeiro, como uma parte rejeitada em si mesmas. Marcos (2017) também aborda o sofrimento na gravidez como uma manifestação de sombra na maternidade, na medida em que ela não solucionaria a castração, mas evidenciaria o furo, o ilusório abarcamento do real pelo simbólico.

Em estudos sobre depressão gestacional, Zucchi (2000) entende que o afeto deprimido ou melancólico na gestação aponta para o sentimento de perda de si, para o trabalho de luto da posição da mulher-filha para a posição da mulher-mãe. Há ainda a condição do filho real enquanto um corpo familiar, porém, desconhecido, gerando sentimento de estranheza e ameaça e conduzindo a mulher a também realizar o trabalho de elaboração sobre o filho gestado. Dessa maneira, ocorre uma reorganização global da subjetividade feminina, podendo fazer emergir traços infantis recalcados e retornar à posição de desamparo originário.

A autora sublinha que as alterações corporais que derivam da gestação de um filho criam marcas profundas no psiquismo da mulher. Como o maior dos rituais de passagem, o período gestacional impetra a impossibilidade de volta ao estado anterior de não mãe e impõe a assustadora e inexorável condição materna. Sentimentos de angústia e dúvidas podem ser componentes da dinâmica melancólica relativa à depressão na gravidez.

Neste estudo, tomaremos o afeto deprimido em muitos de seus matizes de manifestação. Consideraremos desde o sentimento de tristeza e alterações de apetite e de sono, até a gravidade da depressão enquanto entidade nosográfica da psiquiatria. Diagnosticada ou não como patologia, adotaremos, conforme Zucchi (2000), a compreensão sobre os estados deprimidos como efeito do processo subjetivo relativo à maternidade, e não como a revelação de uma estrutura melancólica.

Em pesquisas sobre a maternidade, a autora concluiu que mesmo em gravidezes planejadas, a mulher pode experimentar depressão e sentimentos de estranheza inéditos em sua trajetória de vida. Não é necessário, portanto, uma determinada estrutura psíquica para que ocorram esses episódios de angústia, bem como não é possível caracterizar um quadro melancólico sustentado por esses episódios.

Silva (2014) elucida que a gravidez é o período de maior prevalência de transtornos mentais na mulher, sobretudo a depressão. As alterações podem ser percebidas pelo humor rebaixado; por dificuldades em falar, andar e manter relações sociais; pela irritabilidade, lentidão e labilidade emocional; por pedidos de ajuda e ideias suicidas. A autora destaca que 


\section{MLE INTERACÃO EM 27. PSICOLOGIA}

a questão da maternidade potencializa o estresse de forma multifatorial, relacionando-se a fatores orgânicos, hormonais, conjugais, familiares, socioculturais e subjetivos da mulher. Há, por isso, dificuldade em detectar e tratar essa demanda de maneira adequada.

As consequências da depressão gestacional podem afetar a saúde da mãe e do bebê por meio de mecanismos de fuga, como a diminuição ou o aumento extremo da ingestão alimentar, maior consumo de álcool e demais drogas, insônia, não adesão ao pré-natal, podendo acarretar baixo crescimento e peso fetal, prematuridade e mortalidade neonatal. A abrangência desse tema alcança o campo da saúde pública, e a importância em desvendar os significados e as reais necessidades de cuidado nessa fase deveria ser de interesse de todos (Zucchi, 2000).

Simas et al. (2013) entrevistaram mulheres durante a gravidez e identificaram que, dentre as transformações que ocorrem em nível biológico, social e psicológico, a prioridade destacada pelas gestantes foi a disponibilidade emocional do cônjuge. Elas relataram que o apoio e a atenção do marido foram fundamentais para que pudessem suportar inseguranças, inexperiência e ambivalências desse período. Os autores afirmam que a paternidade iniciada antes do nascimento proporciona o envolvimento afetivo do homem com a mulher e com o filho, favorecendo a criação de vínculos familiares saudáveis.

Fiterman e Moreira (2018) identificaram múltiplas possibilidades para a transição para a paternidade. Para as autoras, fatores como os graus de planejamento e de desejo influenciarão o processo de transformação do homem ao se tornar pai ainda durante a gravidez, atravessando contínuas mudanças na construção do relacionamento entre ele e seu filho.

A função do pai do bebê durante a gestação é determinante na redução da ansiedade e medos maternos. 0 desejo paterno pelo filho gestado e o sentimento da mãe em ser amada pelo marido enquanto mulher influenciam o processo de subjetivação da criança e reduzem a sobrecarga referente às tarefas da maternidade (Gomes et al., 2015). Nesse sentido, o contexto promovido pelo laço conjugal bem estruturado torna-se fundamental para a vivência materna de emoções positivas durante a gravidez.

No paradigma winnicottiano, para que a mãe acolha o bebê, ela precisa também de um ambiente favorável para além de suas condições intrapsíquicas. Silva (2016) retoma essa concepção, considerando que o primeiro papel do pai será fornecer o continente afetivo para a díade mãe-bebê, garantindo-lhes noções de segurança e continuidade. Sustentando o estado materno de gestação, contemplando desafios e ansiedades desse momento, o pai cumpre a função de assegurar proteção e cuidado à mulher, ao filho e às relações dentro da família.
Contudo, o vínculo conjugal pode estar fragilizado antes da gestação, podendo ser desfeito em meio às demandas parentais constituídas a partir da gravidez. Segundo Magalhães e Féres-Carneiro (2011), as exigências da parentalidade evidenciam o desamparo dos cônjuges, rompendo com a ilusão de completude e pondo em risco a sobrevivência psíquica do casal conjugal. Dessa forma, quando a dimensão da conjugalidade não é bem estruturada e demarcada, a construção da dimensão parental pode ser comprometida. 0 casal que espera um bebê, momento de origem da família, é responsável pelo desenvolvimento das funções psíquicas que promoverão estabilidade e segurança aos seus membros: continência, ligação e transformação, como postula Eiguer (1998).

Palermo et al. (2016) retomam a noção winnicottiana de ambiente facilitador, compreendendo a conjugalidade dos pais como parte fundamental para o desenvolvimento psíquico do filho. As autoras destacam que a qualidade da relação entre os membros do casal será a origem para a maturidade emocional dos descendentes. Com efeito, um espaço transicional conjugal imaturo prejudicará as trocas intersubjetivas entre os membros da família e conduzirá ao esmaecimento do potencial criativo do filho.

Nos casos em que os cônjuges apresentam fragilidade nas identidades individuais e, portanto, vulnerabilidade na identidade conjugal, as funções parentais que sustentarão a formação da família poderão encontrar dificuldades no seu desenvolvimento. Ademais, em um contexto social em que percebemos sofrimento decorrente de sentimentos de solidão, desamparo e insegurança, como apontam Oliveira et al. (2014), a prevenção e o tratamento a essa demanda podem ser ainda velados ou subestimados.

Concebendo a gravidez como um período de fragilidade física e psíquica, em que a mulher demanda relações de cuidado e amparo, faz-se necessário compreender as dinâmicas conjugais e as vivências emocionais que ocorrem nessa fase. Para tanto, este trabalho teve como objetivo investigar os afetos vivenciados durante a gestação por mulheres que, posteriormente, se separaram.

\section{MÉTODO}

A fim de investigar a vivência feminina do processo de separação conjugal na transição para a parentalidade, conforme o objetivo da pesquisa mais ampla, foram recrutadas por amostragem em bola de neve (Vinuto, 2014) e entrevistadas 12 mulheres pertencentes ao nível socioeconômico médio da cidade do Rio de Janeiro, heterossexuais, que tinham coabitado com o pai do seu primeiro filho por ao menos dois anos, com idades entre 30 e 40 . 0 período de maior tensão conjugal varia da gravidez até o vigésimo quarto mês do bebê, podendo 
gerar uma crise na conjugalidade (Curran et al., 2006). Assim, foi critério de inclusão das participantes que elas tenham se separado durante esse período.

Foi utilizada uma Ficha Biográfica e realizada uma entrevista em retrospectiva que teve como base um roteiro oculto semiestruturado, contemplando temas concernentes ao objetivo do estudo. Desse modo, a pesquisadora pôde seguir a direção dada pelos entrevistados sem ficar presa a uma sequência rígida de perguntas. Os eixos temáticos que compuseram o roteiro oculto foram os seguintes: breve história da relação amorosa, casamento, gravidez, rede de apoio, relação amorosa depois do filho, conflitos, motivações para a separação e transformações após a separação. As entrevistas tiveram duração média de 50 minutos, foram realizadas individualmente, gravadas e transcritas. Foram realizadas com o período de, no mínimo dois anos e, no máximo, cinco anos da separação das participantes.

Para a análise do material obtido, foi utilizado o método de análise de conteúdo, na sua vertente categorial, tal como proposto por Bardin (2016). Os relatos das entrevistadas narraram histórias individuais em cronologias próprias. Percebemos processos comuns no discurso das participantes e organizamos as categorias em uma linha do tempo a fim de melhor analisá-las. No primeiro momento, destacamos a formação do casal conjugal; no segundo momento, a gravidez; no terceiro momento, a chegada do filho e, no quarto momento, o pós-separação. As categorias que emergiram do discurso das entrevistadas no estudo maior foram: dependência absoluta, ilusão de onipotência (primeiro momento), conflitos conjugais pré-existentes, tristeza e depressão na gravidez, sentimentos de rejeição (segundo momento), filho e primeiros cuidados, motivações para a separação (terceiro momento), paternidade após a separação conjugal, adaptação ao novo arranjo familiar e imaginário social sobre a mãe separada (quarto momento). A fim de cumprir com o objetivo deste estudo, abordaremos as categorias de análise conflitos conjugais pré-existentes, tristeza e depressão na gravidez e sentimentos de rejeição.

0 projeto que deu origem a este estudo foi aprovado pelo Comitê de Ética em Pesquisa da instituição onde o estudo foi desenvolvido (Parecer 003D/2017). As participantes assinaram o Termo de Consentimento Livre e Esclarecido, tendo autorizado o uso dos resultados da investigação em ensino, pesquisa e publicação, preservadas suas identidades.

Tabela 1: Dados biográficos das participantes

\begin{tabular}{|c|c|c|c|c|c|c|}
\hline Participantes & Idade & $\begin{array}{l}\text { Tempo de separação } \\
\text { (em relação ao momen- } \\
\text { to da entrevista) }\end{array}$ & $\begin{array}{l}\text { Idade do (a) filho } \\
\text { (a) na separação }\end{array}$ & Trabalha & Tipo de guarda & $\begin{array}{l}\text { Rede de de } \\
\text { cuidadores }\end{array}$ \\
\hline Mulher 1 & 33 anos & 4 anos e seis meses & 1 ano e 6 meses & $\operatorname{sim}$ & unilateral & $\begin{array}{l}\text { Avó, babá e } \\
\text { empregada }\end{array}$ \\
\hline Mulher 2 & 34 anos & 4 anos & 1 ano e 1 mês & $\operatorname{sim}$ & unilateral & Avó \\
\hline Mulher 3 & 35 anos & 5 anos & $\begin{array}{l}1 \text { ano e seis me- } \\
\text { ses }\end{array}$ & $\operatorname{sim}$ & compartilhada & Avós \\
\hline Mulher 4 & 37 anos & 5 anos & 1 ano & não & compartilhada & $\ldots$ \\
\hline Mulher 5 & 34 anos & 4 anos & 10 meses & $\operatorname{sim}$ & unilateral & $\ldots$ \\
\hline Mulher 6 & 34 anos & 5 anos e seis meses & $\begin{array}{l}1 \text { ano e seis me- } \\
\text { ses }\end{array}$ & $\operatorname{sim}$ & unilateral & Bisavós \\
\hline Mulher 7 & 38 anos & 3 anos & 1 ano & não & unilateral & Avó \\
\hline Mulher 8 & 40 anos & 4 anos & 2 anos & $\operatorname{sim}$ & compartilhada & Avós \\
\hline Mulher 9 & 32 anos & 5 anos & 6 meses & $\operatorname{sim}$ & unilateral & - \\
\hline Mulher 10 & 30 anos & 2 anos e seis meses & 1 mês & $\operatorname{sim}$ & compartilhada & Avó \\
\hline Mulher 11 & 40 anos & 2 anos & $\begin{array}{l}1 \text { ano e seis me- } \\
\text { ses }\end{array}$ & $\operatorname{sim}$ & compartilhada & Avós \\
\hline Mulher 12 & 34 anos & 5 anos & 2 anos & não & unilateral & Avó \\
\hline
\end{tabular}

Obs.: todas as participantes relataram ter o nível de escolaridade relativo ao ensino superior completo e tiveram somente um filho. 


\section{TIERACÃO EM ET. PSICOLOGIA}

\section{ANÁLISE E DISCUSSÃO DOS DADOS}

A partir das narrativas das entrevistadas, emergiram três categorias de análise referentes aos afetos por elas vivenciados: conflitos conjugais pré-existentes, tristeza e depressão gestacional e vivências de rejeição.

Conflitos conjugais pré-existentes. A maioria das entrevistadas (nove) mencionou uma intensa vivência de insatisfação com a relação conjugal durante o período gestacional. Elas ressaltaram que foi uma fase difícil, de crise na conjugalidade, caracterizada por suspeitas de infidelidade dos maridos, falta de companheirismo e de cuidados com elas e com o bebê. Observamos que no caso de algumas, foi a partir da gestação que puderam de fato entrar em contato com aspectos de seus maridos anteriormente negados, evidenciando a própria fragilidade da relação.

Eu não podia beber na gravidez, né? Aí parecia que ele tinha que beber pelos dois. Exagerava na cerveja e ficava meio agressivo (...) parecia que tinha raiva de mim por eu estar grávida e não poder mais beber com ele. (Participante 2)

Durante a gravidez ele começou a me tratar mal. Ele vivia falando que eu tava gorda, feia, que não me cuidava. Ainda bem que eu descobri tarde (gravidez), porque foi a pior fase da minha vida. Ali a nossa relação começou a desandar (...) Eu comecei a desconfiar de traição e fiquei muito mal. Hoje eu vejo como eu fiquei mal. (Participante 4)

Eu não sabia o que ia ser, o que ia acontecer e ao mesmo tempo, eu tava conhecendo mais o pai da minha filha e ficando horrorizada. E o medo da gravidez em si, né? (...) Só depois que eu engravidei que eu vi que ele era usuário de cocaína frequente. (...) Eu amava ele de uma forma louca, que não é normal. Acho que era só uma paixão louca que tava chegando no final, mas só que eu engravidei. (Participante 5)

A gente já tava naquele esgarçamento do relacionamento, já tinha quase dez anos, eu pensando profundamente, refletindo o ano inteiro sobre terminar com ele, mas eu tava elaborando esse término internamente, sem ter condições de terminar de fato. Eu sabia que aquele relacionamento não ia durar. (Participante 6)

Quando eu engravidei, ele não aguentou a barra e foi se afastando. (...) Desconfiei que ele tava me traindo porque ele continuou trabalhando com festa à noite e, sabe como é, né? Fiquei no chão. (...) Queria agradar ele, mas com o tempo vi que seria impossível. (Participante 7)

O cara não tinha muita iniciativa, era só eu cuidando de tudo. (...) A nossa relação também já não tava legal. Era muito zelo, muito cuidado que eu tinha com ele, eu virei mais mãe que mulher. (Participante 12)

Como pudemos perceber nas falas, as mulheres relataram que a gravidez evidenciou a vulnerabilidade do laço conjugal, ressaltando que os maridos não foram bons companheiros durante a gestação. Segundo as narrativas das entrevistadas, o comportamento deles foi percebido como um desinteresse conjugal, fazendo com que elas também desinvestissem do casamento. Podemos pensar que o fato de elas terem deixado de se sentir desejadas e amadas enquanto mulheres, conforme explicam Gomes et al. (2015), pode ter contribuído para as dificuldades durante a gravidez, sobretudo para o aumento de vivências afetivas desvitalizadoras.

Nesse sentido, ao não encontrarem um companheiro para compartilhar a construção do bebê imaginário, as mulheres parecem ter se sentido sozinhas na preparação psicológica do casal parental para a chegada do bebê (Brazelton \& Cramer, 1992). Com base na visão delas, podemos inferir que os homens não realizaram o trabalho psíquico compartilhado de construção do bebê interno. Assim, podemos pensar que a falta de investimento paterno no bebê imaginário pode ocasionar dificuldades para a mulher na fase de gestação e mesmo após o nascimento.

Podemos entender que o papel paterno de fornecer um ambiente afetivo capaz de acolher, proteger e assegurar a continuidade da dupla mãe-bebê, conforme ressalta Simas et al. (2013), parece não ter sido bem realizado. As narrativas evidenciam a importância de as mulheres terem apoio de seus companheiros já nesse período inicial, possivelmente sendo continente das fragilidades psíquicas naturais desta fase. 0 estado materno de gestação não foi, portanto, bem sustentado pelo parceiro, tendo tido como efeito o aumento da ambivalência da mulher em relação ao bebê, a si mesma e ao casamento. Como podemos verificar nos trechos destacados.

Eu gostava muito da nossa vida de 'vamos viajar, vamos fazer e acontecer!' E aquela responsabilidade no relacionamento foi acabando com tudo. (...) Aí eu fiquei bem 'deprê', eu fiquei bem 'deprê' mesmo. Não foi fácil. Isso me gerou uma insegurança muito grande. (...) Eu tava feia, não podia fazer nada e ele podia fazer o que quisesse. Ele tava livre e eu não. Isso gerou uma inveja, uma raivinha dele. (...) Raiva por eu ter que ser a grávida. Por que não podia ser ele? Eu não curti nada. Eu cheguei a pensar: 'se eu tiver atravessando a rua e um carro me pegar, eu ia gostar'. Eu nunca tinha tido um pensamento assim na vida. (Participante 3 )

Eu engordei e ele já não olhava mais pra mim como antes (...) eu via ele olhando pra outras mulheres (...) Eu olhava pra escada no trabalho e pensava que podia mudar aquilo tudo, mas achava que o errado era ele e não eu ou o bebê (...) Não achava que ia ser daquele jeito. (Participante 8) 


\section{MLE INTERACÃO EM LF PSICOLOGIA}

A partir das falas, constatamos também que o casal conjugal apresentou dificuldades de sustentar a criação do casal parental, ou seja, de realizar reformulações no acordo relacional. A ilusão conjugal de irresponsabilidades e de tudo ser possível parece ter sido rompida com o início da gravidez.

Nessas condições, as fragilidades conjugais parecem ter sido potencializadas com a gestação, ameaçando a permanência do casal diante da construção de uma nova parceria exigida pela parentalidade. Esses dados podem ser compreendidos a partir dos resultados encontrados por Magalhães e Féres-Carneiro (2011) acerca da interdependência entre as dimensões da conjugalidade e da parentalidade e, sobretudo, de situações em que a primeira sucumbe às demandas da segunda.

Não foi bem construído um ambiente facilitador com base no espaço transicional conjugal, tal como conceituado por Palermo et al. (2016). A imaturidade emocional dos cônjuges parece ter obstruído as trocas parentais que se iniciam durante a gravidez, repercutindo na formação da díade mãe-bebê e na formação da família.

Tristeza e depressão na gravidez . Nas narrativas destacadas a seguir, podemos perceber uma gradação na manifestação de afetos deprimidos ao longo da gravidez. As entrevistadas relataram que durante a gravidez os afetos e vivências mais presentes estavam relacionados à impaciência, isolamento, insegurança, tristeza, até mesmo depressão e ideias suicidas.

Eu acho que eu fiquei bem impaciente durante a gravidez. (...) Me isolei um pouco, me afastei dele (do marido), sei lá. (Participante 1)

Fiquei muito perdida, sabe? Me senti um pouco pesada assim. Era muita incerteza sobre o futuro. Mas era muito amor também. Eu fiquei muito estressada porque era muita responsabilidade em cima de mim. (...) Rolou um clima de insegurança, sabe? (Participante 5)

Foi uma coisa muito terrível pra mim. (...) Então ali eu entrei numa depressão profunda. Eu tive depressão gestacional com risco de suicídio. Foi muito ruim. Meu pré-natal foi complicado porque eu perdia as consultas, eu não conseguia sair de casa, não conseguia sair da cama. (...) Mas eu tava numa crise tão profunda que eu entrei na maternidade sem saber se eu sairia com a criança de lá. Não sabia se deixaria o bebê com ele e terminaria tudo ali. Eu entrei louca na maternidade. (Participante 6)

Nessa fase eu acho que tava em depressão profunda. Eu só queria ficar no quarto escuro e nem deixava as minhas amigas entrarem pra me ver. (...) Tive que ir ao psiquiatra e fazer terapia durante a gravidez. (Participante 7)
Foi uma gravidez bem difícil porque eu enjoei muito, tive que interromper os meus estudos. Eu passei os nove meses vomitando, umas três vezes por dia. Muito ruim. Fiquei nove meses passando muito mal.Física e emocionalmente foi bem complicado pra mim, tive momentos bem complicados. (Participante 12)

As falas evidenciam uma experiência negativa da gravidez, na qual estavam presentes formas de sofrimento que levaram à regressão e ao isolamento das entrevistadas. Elas relataram o distanciamento do cônjuge, de amigos e de atividades sociais durante a gestação. 0 movimento de regressão que possibilitou o acesso a conteúdos inconscientes foi também estudado por Bydlowiski (2002) como uma condição da muIher grávida que, ao fantasiar sobre o filho, acessa conteúdos pré-edípicos e reedita a própria infância. Esse movimento parece ter sido vivenciado pelas entrevistadas como um retorno à posição de desamparo originário, acentuando-se quando não encontraram continência no ambiente conjugal, revelando fragilidades e medos diante do ineditismo da maternidade e em relação às bases que tinham construído suas vidas.

Para além do trabalho de luto da transição da mulher-fiIha para a mulher-mãe, identificado por Zucchi (2000) como principal gerador do afeto deprimido na gestação, podemos marcar ainda o trabalho de luto da relação conjugal como catalisador do sofrimento vivenciado pelas participantes durante a gravidez. Ao desinvestirem do relacionamento amoroso, elas podem ter potencializado os sentimentos de ameaça e de despersonalização, sendo imersas na condição de desamparo emocional nesse período.

A tristeza e a depressão durante a gravidez podem ser compreendidas como a expressão da perda da ilusão de completude relacionada à beleza, à juventude e à satisfação conjugal plena. As entrevistadas parecem ter sido levadas a perceber a impossibilidade de uma relação parental sem parceria, tendo sido confrontadas pelo trabalho de amadurecimento psíquico posto pela gestação e desconstruindo defesas que pareciam negar a passagem do tempo e a falência conjugal.

Sentimento de rejeição. As falas a seguir apresentam uma assimetria conjugal em relação aos afetos e às formas de lidar com o surgimento da parentalidade. Nas mulheres as transformações corporais da gravidez eram impostas, despertando rejeição em relação aos sintomas e às naturais consequências desse estado, como o aumento de peso. Percebiam seus maridos vivendo uma antiga vida, já conhecida e "dominada", portanto, sem surpresas e incertezas, da qual não conseguiram se despedir, nem se disponibilizarem para uma transformação.

A gravidez não era desejo de nenhum dos dois. Mas, na minha cabeça não tinha a menor possibilidade de eu não ter o L., até porque eu sempre quis ser mãe. (...) Antes a gente saía e bebia todas. Depois da gravidez só ele continuou 


\section{H. INTERACÃO EM LF PSICOLOGIA}

bebendo, né? Eu tive muito ciúme dele, eu ligava e ia atrás dele na rua. Era como se o filho me prendesse a ele. Aí teve uma hora que eu aceitei ser mãe solteira. (...) Não existe a obrigatoriedade de ficar com ninguém. (Participante 3)

Ele nunca foi a uma ultra ver como tava o filho dele, ele não me acompanhava a médico, a lugar nenhum. Ele ficou muito distante na gravidez. Ele continuou com a vida dele normal e nem tava aí pro que eu tava sentindo. (Participante 4)

Eu não ia nas ultras e a minha autoestima desapareceu. Eu via o meu corpo mudando e foi bem difícil porque eu malhava e treinava muito.Fiquei me sentindo mal, gorda, feia. Não foi fácil. Fiquei muito insegura sobre o futuro das nossas vidas. (...) Ele não queria ter filho. Acho que como o pai rejeitou o filho, eu tava rejeitando também. Eu tentava mas, não tava feliz com aquilo tudo. A gente vê as grávidas felizes, como se tivessem sonhando e parecia que eu tava vivendo um pesadelo.(Participante 7 )

Como é possível observar, as narrativas das participantes ressaltaram o sentimento de rejeição do marido em relação ao filho gestado e a elas mesmas. Uma delas afirma que a rejeição do marido levou à rejeição dela própria ao seu filho. Podemos considerar que as mudanças na rotina da mulher grávida não foram acompanhadas por alterações na rotina do marido.

Considerando a gravidez como uma fase em que o desconhecido é representado pelo bebê, e a mãe pode significá-lo como uma parte estranha em si mesma, conforme analisa Solano-Suarez (2014), a rejeição do pai pode ter aumentado a sensação do filho como parte estrangeira e negada da própria mulher, enquanto mãe. Dessa forma, elas podem ter experimentado a ambivalência entre desejar e rejeitar o próprio filho, talvez ainda guiadas pela intenção de recuperar a relação conjugal e o estado de mulher-filha.

O sentimento de rejeição pode ainda ter feito emergir aspectos psíquicos negados e desintegrados das entrevistadas, como descreve Moura (2013). Podemos pensar que elas se identificaram com a polaridade de ódio em relação ao filho, ao localizarem nele a razão pela falência conjugal. A rejeição ao filho como limitador de sua liberdade e como causador de conflitos conjugais pode ter sido ancorada pela rejeição do marido à dupla mãe-bebê.

Contudo, as falas apontaram para transformações que ocorreram primordialmente nas vidas das mulheres durante a gravidez. Até esse momento, as entrevistadas não apontaram para modificações realizadas no cotidiano de seus ex-cônjuges como forma de compartilhar as idas aos exames pré-natais ou mesmo as saídas com amigos. Ao contrário do que afırmam Fiterman e Moreira (2018) sobre a transição para a paternidade, as mulheres relataram que os pais não foram significativamente transformados pela nova posição de pai, nem no que diz respeito a mudanças subjetivas nem pelo reconhecimento de novas funções durante a gestação.

\section{CONSIDERAÇÕES FINAIS}

De acordo com as narrativas analisadas, podemos compreender a vivência da gravidez como uma fase de múltiplos lutos, por meio dos quais as entrevistadas descortinaram realidades antes encobertas. As participantes relataram um período em que atravessaram profunda transformação psíquica, experimentando afetos difíceis e entrando em contato com aspectos de suas personalidades no caminho da elaboração da maternidade e do abandono da posição de filhas.

Os relatos destacaram que houve uma mudança nas muIheres que não foi acompanhada pelo amadurecimento da relação conjugal, cuja característica predominante era a manutenção de sensações como menos responsabilidade, liberdade individual e constante satisfação. Elas identificaram falta de parceria e de companheirismo com os parceiros, apontando para dificuldades de o casal conjugal suportar as transições do ciclo vital e as implicações de ser um casal parental.

Esperar por um filho parece ter significado para elas inicialmente uma ameaça, o fim do estilo de vida em que se apoiavam, na medida em que se sentiram limitadas e perceberam que a gravidez exigiria o desinvestimento das concepções de casamento, de vida e de seus padrões anteriores e idealizados de ser. Elas parecem ter construído com seus cônjuges uma fantasia conjugal que foi sendo desconstruída pelos dados de realidade que surgiam com a transição para a parentalidade.

As participantes constataram ter percebido uma vulnerabilidade conjugal durante a gestação, o que nos leva a considerar a concomitante vivência de luto da relação amorosa neste momento. A conjugalidade imatura e frágil parece não ter resistido às exigências impostas pela parentalidade. Segundo elas, os maridos não cumpriram a função de continência para as mulheres, e o casal não funcionou como ambiente facilitador e promotor de saúde para a gestação e para a formação de uma família.

Elaborar o lugar de mulher-mãe para além do lugar de muIher-filha, lidar com o fim de um casamento e com a ideia de ter falhado em constituir uma família pareceu um trabalho psíquico insuportável para as entrevistadas, o que contribuiu para avaliarmos o fenômeno da depressão na gravidez não como distúrbio ou transtorno intrapsíquico exclusivos da muIher, mas abarcando aspectos relacionais que compuseram a realidade em que viviam. Entender o contexto em que essas mulheres constroem o novo lugar de mãe é fundamental para desconstruirmos a idealização sobre a maternidade e reconhecermos as dificuldades experimentadas por elas na situação estudada. Romantizar esse período pode ser uma armadilha às 


\section{H* INTERACÃO EM PSICOLOGIA}

demandas de cuidado e uma barreira aos pedidos de ajuda ao longo de todas as transformações atravessadas. 0 tempo de gestação pode acontecer em diferentes situações conjugais, familiares e sociais, podendo assumir significados variados e devendo ser legitimado em todas as suas manifestações.

Mostrou-se importante a ampliação sobre a atenção e o tratamento às mulheres grávidas, por meio da compreensão sobre o contexto familiar e subjetivo em que ocorrem formas de sofrimento, evitando a atribuição de culpa ou julgamento sobre elas. 0 período de extrema sensibilidade e transparência psíquica pode colocá-las diante de conteúdos de difícil elaboração e expor suas identidades a situações excessivamente delicadas.

O sentimento de rejeição em relação a si mesmas e aos seus filhos, vindo daquele que seria o primeiro suposto a realizar as tarefas de proteção e cuidado, parece ter exercido impacto incapacitante no período de gravidez de algumas entrevistadas. 0 bebê esperado não funcionaria como o projeto de manutenção do casamento, mas como aquele que denunciaria sua falha. Assim, as mulheres parecem ter feito um movimento de amadurecimento diante de uma visão infantil e romantizada de suas concepções conjugais, rompendo também com padrões culturais idealizados sobre casamento e família.

Ficou evidente a necessidade de acolhimento, escuta e cuidado das mulheres que ofereçam a possibilidade de metabolizar as dores psíquicas desse período. É fundamental a constante atualização de profissionais que lidem com o fenômeno da maternidade, sobretudo os que atendem às demandas afetivas, na direção de desnaturalizarem e livrarem-se de preconceitos relativos ao processo de se tornar mãe e de transformações na conjugalidade.

0 afeto deprimido, como uma tristeza profunda relacionada às fragilidades psíquicas da identidade e da relação conjugal, que parecem ter contribuído para os quadros de depressão gestacional, emergiu como o aspecto mais significativo nas narrativas, conduzindo as investigações sobre esse tema e suas possíveis relações com a posterior separação. Esse estado emocional pode ser compreendido como uma dificuldade durante a gravidez mas, por outro lado, também pode ser uma manifestação das mulheres na direção da saúde psíquica, conjugal e parental. A manutenção da gravidez, mesmo sem o apoio do parceiro, pode indicar a busca por maturidade emocional e continuidade psíquica por meio do exercício do novo papel de mãe. Desta forma, estudos futuros podem aprofundar essa temática a fim de melhor compreender esse fenômeno em diversas configurações conjugais e familiares.

\section{FINANCIAMENTO:}

Não houve financiamento.

\section{DECLARAÇÃO DA CONTRIBUIÇÃO DOS AUTORES:}

Certificamos que todos os autores participaram suficientemente do estudo para tornar pública sua responsabilidade pelo conteúdo. A contribuição de cada autor pode ser atribuída como se segue:

M. R. B. exerceu administração, análise e tabulação dos dados, conceitualização, investigação, redação e visualização. R. N. M. exerceu conceitualização e redação. T. F. C. exerceu supervisão e redação.

\section{DECLARAÇÃO DE POTENCIAIS CONFLITOS DE INTERESSE:}

As autoras declaram que não há conflitos de interesse no manuscrito submetido.

\section{REFERÊNCIAS}

Bardin, L. (2016). Análise de conteúdo.: Edições 70.

Brazelton, B., \& Cramer, B. (1992). As primeiras relações. Martins Fontes.

Bydlowski, M. (2002). O olhar interior da mulher grávida: Transparência psíquica e representação do objeto interno. In: Corrêa Filho, L., Corrêa Girade, M. H. \& França, P. (Orgs.). Novos olhares sobre a gestação e a criança até 3 anos: saúde perinatal, educação e desenvolvimento do bebê.: L.G.E. Editora.

Curran, M., Hazen, N., Jacobvitz, D., \& Sasaki, T. (2006). How representation of the parental marriage predict marital emotional attunement during the transition to parenthood. Journal of Family Psychology, 20(3), 477-484. https://www. scielo.br/scielo.php?script=sci_nlinks\&ref=000131\&pi$\mathrm{d}=$ S1413-8271200700010001000009\&Ing=en

Eiguer, A. (1998). A transmissão do psiquismo entre gerações: enfoque em terapia familiar psicanalítica.: Unimarco Editora.

Fiterman, H., \& Moreira, L. V. C. (2018). O pai na gestação, no parto e aos três meses de vida do primeiro filho. Polis (Santiago), 17(50), 47-68. https://scielo.conicyt.cl/pdf/polis/ v17n50/0718-6568-polis-17-50-00047.pdf.

Golse, B., \& Bydlowski, M. (2002). Da transparência psíquica à preocupação materna primária: uma via de objetalização. In: Corrêa Filho, L., Corrêa Girade, M. H. \& França, P. (Orgs.). Novos olhares sobre a gestação e a criança até 3 anos: saúde perinatal, educação e desenvolvimento do bebê.: L.G.E. Editora.

Gomes, A. G., Marin, A. H., Piccinini, C. A., \& Lopes, R. C. S. (2015). Expectativas e sentimentos de gestantes solteiras em relação aos seus bebês. Temas em Psicologia, 23(2), 399-411. https://doi.org/10.9788/TP2015.2-12. 


\section{- IN INERACÃO EM LF. PSICOLOGIA}

Magalhães, A. S., \& Féres-Carneiro, T. (2011). Em busca de uma conjugalidade perdida: Quando a parentalidade prevalece. In T. Féres-Carneiro (Org.). Casal e família: Conjugalidade, parentalidade e psicoterapia (pp. 161-172). Casa do Psicólogo.

Marcos, C. M. (2017) O desejo de ter um filho e a mulher hoje. Trivium: Estudos interdisciplinares, 9(2), 246-256. https:// doi.org/10.18379/2176-4891.2017v2p.246

Moura, D. (2013). Maternidade e poder. Revista Mal-estar e Subjetividade, 13(1-2) 392- 396. http://pepsic.bvsalud. org/scielo.php?scipt=sci_arttex\&pid=S1518- 614820 1300100015

Oliveira, A. A. A., Resstel, C. C. F. P., \& Justo, J. S. (2014). Desamparo psíquico na contemporaneidade. $R e-$ vista de Psicologia da UNESP, 13, 21-32. http://pepsic.bvsalud.org/scielo.php?script $=$ sci_arttext $\&$ pi$\mathrm{d}=S 1984-90442014000100003 \&$ Ing $=p t \& t \operatorname{lng}=p t$

Palermo, F. R., Magalhães, A. S.; Féres-Carneiro, T., \& Machado, R. N. (2016). Ambiente conjugal: repercussões na parentalidade. Cadernos de psicanálise (Rio de Janeiro), 38(34), 129-148.

Rena, A. C. C. B.; Romagnoli, R. C., \& Lima, N. L. (2014). Maternidade e feminilidade: um estudo da subjetividade de mães negligentes na Assistência Social. Revista Latinoamericana de Psicopatologia Fundamental, 17(4), 845-857. https://dx. doi.org/10.1590/1415-4714.2014v17n4p845.3
Silva, C. R. (2014). Depressão gestacional: uma revisão de literatura. Monografia de conclusão de Curso de especialização em linhas de cuidado em enfermagem. Universidade Federal de Santa Catarina,

Silva, S. G. (2016). Do feto ao bebê: Winnicott e as primeiras relações materno-infantis. Psicologia Clínica, 28(2), 29-54. http://pepsic.bvsalud.org/pdf/pc/v28n2/03.pdf

Simas F. B., Souza L.V. \& Scorsolini-Comin F. (2013) Significados da gravidez e da maternidade: discursos de primíparas e multíparas. Psicologia Teoria e Prática, 15(1), 93-102. http://pepsic.bvsalud.org/scielo.php?script=sci_arttext\&pi$\mathrm{d}=S 1516-36872013000100002 \&$ Ing $=p t \&$ tIng $=p t$

Solano-Suárez, E. (2014). "Maternité Blues". In (Sous la direction) Être mère. Navarin/Le Champ Freudien.

Vinuto, J. (2014) A amostragem de bola de neve em pesquisa qualitativa: um debate aberto. Temáticas, 22(44), 203-220.

Winnicott, D.W. (1956). A preocupação materna primária. In D. W. Winnicott. Da pediatria à psicanálise: Obras Escolhidas. Imago.

Zucchi, M. (2000) Estranhas Entranhas: Psicanálise e Depressão na Gravidez. Fiocruz.

Submetido em: $23 / 04 / 2020$ Primeira decisão editorial em:18/12/2020 Aceito em: 15/02/2021 